\title{
Reaction wood anatomy and lignin distribution in Gnetum gnemon branches
}

\author{
Haruna Aiso-Sanada ${ }^{1,2,3} \cdot$ Futoshi Ishiguri $^{1}$ (1) $\cdot$ Denny Irawati ${ }^{4} \cdot$ Imam Wahyudi $^{5} \cdot$ Shinso Yokota $^{1}$
}

Received: 20 March 2018 / Accepted: 7 October 2018 / Published online: 1 November 2018

(C) The Japan Wood Research Society 2018

\begin{abstract}
This study investigated the anatomical and chemical characteristics of the reaction wood of a gymnpsperm species, Gnetum gnemon, and discussed on contributing factor for the type of reaction wood in this species. Cell morphology, microfibril angle (MFA) of the $\mathrm{S}_{2}$ layer and lignin distribution in secondary walls of tracheary elements, and lignin content were examined on three branches. Observations included no G-layer formation, significant decreases in vessel frequency, and altered MFA, and visible-light absorbance after lignin colour reactions in tracheid and fiber tracheid walls on the upper side in almost all samples. These results suggest that reaction wood in G. gnemon was similar to that in 'tension-wood-like-reaction wood' in angiosperms. On the other hand, reaction wood showed decrease in the lignin concentration in the fiber tracheid walls compared to the tracheid walls. In addition, the lignin in the tracheid and fiber tracheid walls was originally rich in syringyl units, suggesting that changes in the anatomical and chemical characteristics of secondary xylem due to reaction wood formation might relate to the ratio of the syringyl to guaiacyl units in lignin in the cell walls which function for mechanical support.
\end{abstract}

Keywords Fiber tracheid $\cdot$ Microfibril angle $\cdot$ Tension wood $\cdot$ Tracheid

\section{Introduction}

Reaction wood is a specific secondary xylem that generally forms on the upper or lower sides of inclined stems or branches in woody plants [1-8]. Species which form reaction wood on the lower side include most of gymnosperms and a few angiosperms [1, 3, 8-11]. Reaction wood in gymnosperm species is known as compression wood and in angiosperms is called "compression-wood-like-reaction wood' [1, 3, 8-11]. Conversely, species which form reaction

Futoshi Ishiguri

ishiguri@cc.utsunomiya-u.ac.jp

1 Faculty of Agriculture, Utsunomiya University, Utsunomiya, Tochigi 321-8505, Japan

2 United Graduate School of Agricultural Science, Tokyo University of Agriculture and Technology, Fuchu, Tokyo 183-8509, Japan

3 Forestry and Forest Products Research Institute, Tsukuba, Ibaraki 305-8687, Japan

4 Faculty of Forestry, Gadjah Mada University, Yogyakarta 55281, Indonesia

5 Faculty of Forestry, Bogor Agricultural University, Bogor 16680, Indonesia wood on the upper side are almost exclusively angiosperms $[2-8,12]$. The reaction woods of this type are usually classified into two types, based on the presence or absence of a gelatinous (G)-layer formation in wood fibers, as tension wood or 'tension-wood-like-reaction wood,' respectively [2, $5-8,12]$.

Gnetum gnemon L. is a gymnosperm species and an evergreen tree distributed in South East Asia. The secondary xylem structure in G. gnemon is similar to that in angiosperms $[13,14]$. Unlike the typical secondary xylem of gymnosperms, which is mainly composed of tracheids, axial parenchyma, and ray parenchyma $[3,8]$, the secondary xylem of G. gnemon contains fiber tracheids and vessel elements in addition to tracheids and parenchyma [13]. The tracheids and fiber tracheids are present at almost the same percentage, but the morphological features differ. The tracheids have a wall thickness of approximately $5 \mu \mathrm{m}$ and distinct bordered pits in their radial and tangential walls, while fiber tracheids have a wall thickness of approximately $2.5 \mu \mathrm{m}$ in wall thickness and have a lesser bordered pits in their radial and tangential walls [13] (Fig. 1).

Tomlinson $[15,16]$ reported the reaction tissue in G. gnemon is formed by the formation of a G-layer in the secondary phloem on the upper side of inclined branches. Recently, 


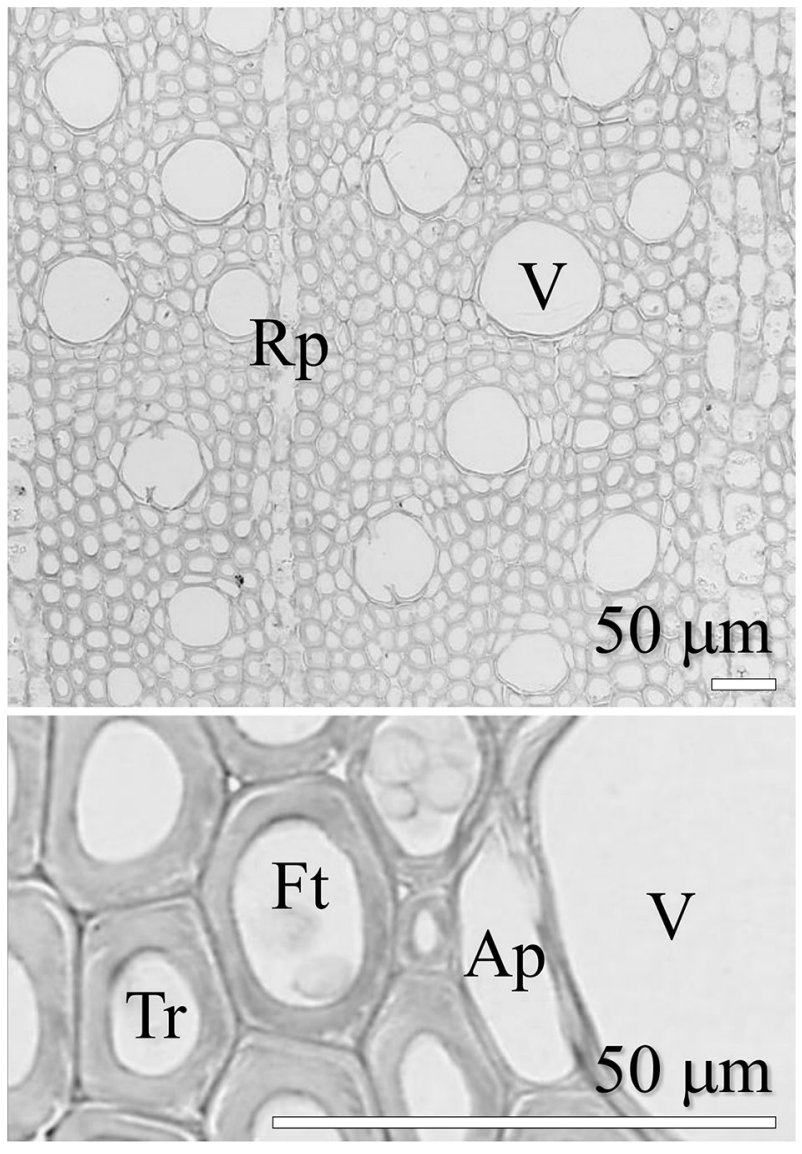

Fig. 1 Photomicrographs of safranin-stained transverse sections from the lower side of Gnetum gnemon sample A. Tracheid wall thickness is approximately $5 \mu \mathrm{m}$ and fiber tracheid wall thickness is approximately $2.5 \mu \mathrm{m}$ [14]. $T r$ tracheid, $A p$ axial parenchyma, $R p$ ray parenchyma, $F t$ fiber tracheid, $V$ vessel. Scale bars $=50 \mu \mathrm{m}$

Shirai et al. [14] reported that inclined G. gnemon stems showed eccentric growth, with excessive tensile growth stress on the upper side. They also reported a lack of G-layer formation in either tracheids or fiber tracheids on both upper and lower sides in secondary xylem of inclined stems. From Shirai et al. [14], it is considered that reaction wood in $G$. gnemon is formed on the upper side of inclined stems or branches, which might be regarded as 'tension-wood-likereaction wood'. However, the details of the alterations of the anatomical characteristics and lignin distribution during reaction wood formation in $G$. gnemon branches are still unclear.

The present study investigated the anatomical characteristics and lignin distribution in the reaction wood in $G$. gnemon branches. The factor which contributes for the type of reaction wood in G. gnemon is discussed based on the findings. The differences in lignin distribution in the two types of tracheids, the tracheid and fiber tracheid, are also discussed.

\section{Materials and methods}

Three branches (samples A, B and C) of Gnetum gnemon were collected from two trees growing at two different sites in Indonesia. Two branches (samples A and B) were collected from a G. gnemon tree growing in Yogyakarta, and the remaining branch (sample $\mathrm{C}$ ) was collected in Bogor, Indonesia. The diameters of the sample branches A, B and C were 2.0, 2.8 and $1.8 \mathrm{~cm}$, respectively. Sample disks $(1 \mathrm{~cm}$ in thickness, Fig. 2) were collected from each sample, and then small blocks were excised from the upper and lower sides. Transverse sections (10 and $15 \mu \mathrm{m}$ in thickness) were prepared from these small blocks using a sliding microtome (REM-710, Yamatokohki). Anatomical characteristics and lignin distribution were separately observed in tracheids and fiber tracheids.

The cell morphology and secondary cell wall structures of vessels, tracheids and fiber tracheids were observed in transverse sections (10 $\mu \mathrm{m}$ thick). Non-stained sections and safranin-stained sections were prepared, and then digital images of the transverse sections were also obtained with an optical microscope (BX51, Olympus), which was equipped with a digital camera (E-P3, Olympus). Vessel frequency, vessel diameter, and wall diameter and thickness
Fig. 2 Photographs of transverse sections of Gnetum gnemon sample discs. Scale bars $=1 \mathrm{~cm}$
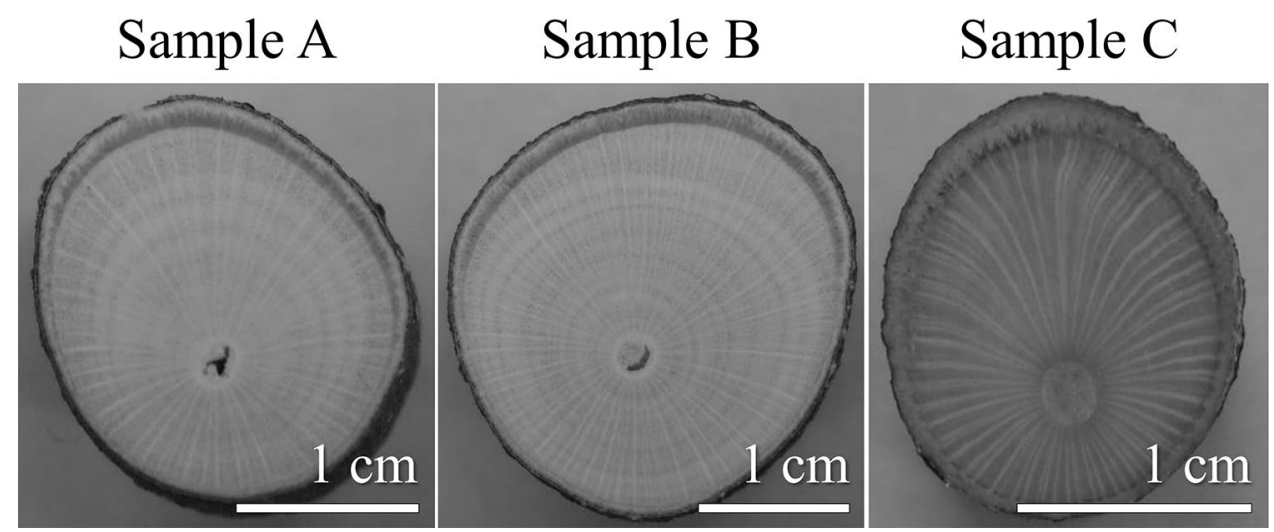
for tracheids and fiber tracheids were measured using ImageJ software (National Institute of Health). In each sample, 30 vessel diameters were measured for radial and tangential directions, respectively. Mean diameter of a vessel was calculated by averaging values in the radial and tangential directions, and then mean vessel diameter in each sample was calculated. For vessel frequency, five transverse digital images were taken from each sample to count the numbers of vessels. Vessel frequency was calculated by dividing the number of vessel into area of the digital image. The average values of vessel frequency were obtained by averaging value of vessel frequency in five images. Tracheids and fiber tracheids were distinguished by their differences in cell wall thickness [13] (Fig. 1). The perimeters of tracheids and fiber tracheids, their lumens and their areas were measured using ImageJ software. The wall thickness of the tracheids and fiber tracheids was calculated as follows [5]:

$W T(\mu \mathrm{m})=A / 0.5(P w f+P l)$,

where $W T$ is average wall thickness in a tracheid or fiber tracheid, $A\left(\mu \mathrm{m}^{2}\right)$ is the area of the tracheid or fiber tracheid, $P w f(\mu \mathrm{m})$ is the perimeter of the tracheid or fiber tracheid, and $P l(\mu \mathrm{m})$ is perimeter of the lumen in the tracheid or fiber tracheid.

Radial sections ( $25 \mu \mathrm{m}$ thick) were also prepared to determine the MFA of the S2 layer of the two types of tracheids. In the present study, the MFA was measured together with these two tracheids, because these two types of tracheids cannot be easily distinguished in radial sections [13]. The MFA was measured using the iodine method described by Senft and Bendtsen [17].
The changes in lignin distribution in each cell wall were determined by measuring the visible-light (VL) absorption spectra of secondary walls in vessels, tracheids and fiber tracheids at $400-650 \mathrm{~nm}$ wavelengths after lignin colour reactions [12]. The mean absorbance values were calculated at 520 and $550 \mathrm{~nm}$ for the Mäule and phloroglucinol-HCl colour reactions, respectively. Lignin content was determined by the acetyl bromide method [18].

All measured data obtained from upper sides were compared to those from lower sides. Significant differences in measured characteristics between upper and lower sides were detected by applying the Student's $t$ test for each sample using a statistical software (Excel 2013, Microsoft).

\section{Results}

Eccentric growth of secondary xylem on the upper side was observed on all samples (Fig. 2). On the other hand, significant decreases were found for the vessel frequency on the upper sides in all samples and for the MFA in the $\mathrm{S}_{2}$ layer of the tracheids, whereas the vessel diameter significantly increased on the upper side of all samples (Table 1; Fig. 3). By contrast, the lignin content significantly decreased only on the upper sides of samples A and B (Table 1).

Significant increases in tracheid and fiber tracheid diameters were observed on the upper sides in all samples (Table 2). Similarly, the wall thicknesses of tracheids and fiber tracheids tended to increase on the upper sides, except for tracheids in sample $A$ (Table 2). A distinct $S_{3}$ layer was observed in the tracheids and fiber tracheids in both the

Table 1 Frequency and diameter of vessels, MFA of the $\mathrm{S}_{2}$ layer in tracheids, and lignin content on the upper and lower sides of branches

\begin{tabular}{|c|c|c|c|c|c|c|}
\hline \multirow[t]{2}{*}{ Property } & \multirow[t]{2}{*}{$n$} & \multirow[t]{2}{*}{ Sample } & \multicolumn{2}{|l|}{ Position } & \multirow[t]{2}{*}{$t$ value ( $p$ value) } & \multirow[t]{2}{*}{$D R(\%)$} \\
\hline & & & Upper & Lower & & \\
\hline \multirow[t]{3}{*}{ Vessel frequency (number of vessels $\mathrm{mm}^{-2}$ ) } & \multirow[t]{3}{*}{5} & A & $36.2(2.2)$ & $52.0(2.9)$ & $9.733(0.00)$ & 30.3 \\
\hline & & $\mathrm{B}$ & $34.7(2.2)$ & $49.4(3.4)$ & $8.033(0.00)$ & 29.8 \\
\hline & & $\mathrm{C}$ & $22.1(3.0)$ & $52.5(8.1)$ & $7.893(0.00)$ & 58.0 \\
\hline \multirow[t]{3}{*}{ Vessel diameter $(\mu \mathrm{m})$} & \multirow[t]{3}{*}{30} & A & $75.5(10.1)$ & $70.7(8.5)$ & $1.993(0.05)$ & -6.8 \\
\hline & & $\mathrm{B}$ & $78.6(6.9)$ & $73.2(8.1)$ & $2.757(0.01)$ & -7.3 \\
\hline & & $\mathrm{C}$ & $75.8(7.7)$ & $60.4(8.0)$ & $7.565(0.00)$ & -25.4 \\
\hline \multirow[t]{3}{*}{ MFA of $\mathrm{S}_{2}$ layer in tracheids $\left(^{\circ}\right)$} & \multirow[t]{3}{*}{30} & A & $10.7(1.5)$ & $21.3(2.7)$ & $18.788(0.00)$ & 49.7 \\
\hline & & $\mathrm{B}$ & $10.7(2.9)$ & $26.4(2.2)$ & $23.562(0.00)$ & 59.5 \\
\hline & & $\mathrm{C}$ & $16.0(2.0)$ & $23.4(2.0)$ & $14.204(0.00)$ & 31.6 \\
\hline \multirow[t]{3}{*}{ Lignin content (\%) } & \multirow[t]{3}{*}{3} & A & $25.6(0.5)$ & $27.8(0.8)$ & $4.185(0.01)$ & 6.8 \\
\hline & & B & $22.3(1.4)$ & $26.2(1.8)$ & $2.930(0.04)$ & 4.7 \\
\hline & & $\mathrm{C}$ & $22.9(1.2)$ & $23.9(0.5)$ & $1.427(0.23)$ & 4.4 \\
\hline
\end{tabular}

The designation ' $n$ ' in vessel frequency indicates the number of photomicrographs, the designation ' $n$ ' in vessel diameter and MFA of $S_{2}$ layer in tracheids indicates number of measured cells, the designation ' $n$ ' in lignin content indicates number of replicates, 'tracheids' indicates both tracheids and fiber tracheids. Values in parentheses indicate standard deviations

$D R$ decrease ratio, which is the ratio of the upper side to the lower side, $M F A$ microfibril angle 
Fig. 3 Photomicrographs of safranin-stained transverse sections on the upper and lower sides of Gnetum gnemon branches in sample A. $R p$ ray parenchyma, $V$ vessel. Scale bar $=100 \mu \mathrm{m}$
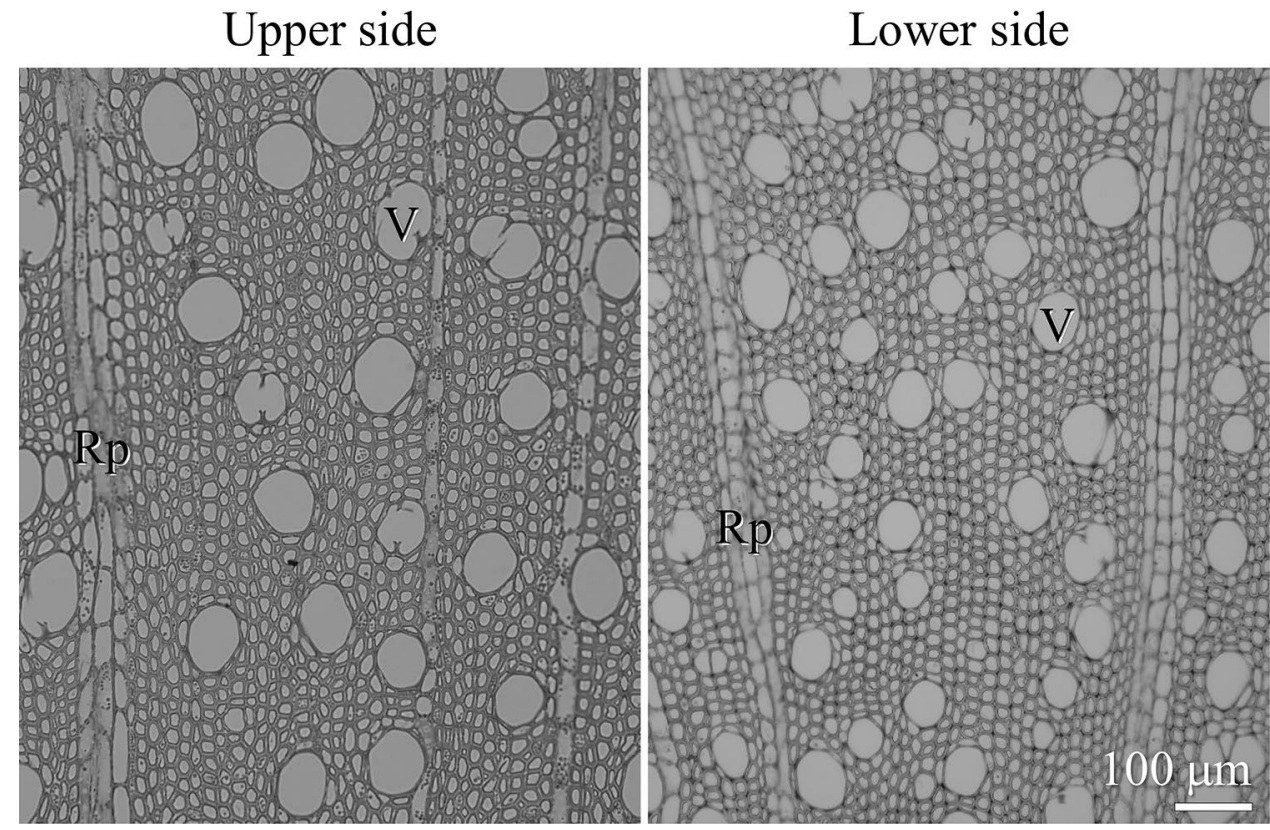

\begin{tabular}{|c|c|c|c|c|c|c|c|}
\hline \multirow[t]{2}{*}{ Cell type } & \multirow[t]{2}{*}{ Property } & \multirow[t]{2}{*}{$n$} & \multirow[t]{2}{*}{ Sample } & \multicolumn{2}{|l|}{ Position } & \multirow[t]{2}{*}{$t$ value ( $p$ value) } & \multirow[t]{2}{*}{$D R(\%)$} \\
\hline & & & & Upper & Lower & & \\
\hline \multirow[t]{6}{*}{ Tracheid } & \multirow[t]{3}{*}{ Diameter $(\mu \mathrm{m})$} & \multirow[t]{3}{*}{50} & A & $23.8(1.8)$ & $21.2(1.9)$ & $6.992(0.00)$ & -12.2 \\
\hline & & & B & $24.8(1.6)$ & $23.7(1.6)$ & $3.450(0.00)$ & -4.6 \\
\hline & & & $\mathrm{C}$ & $24.0(1.8)$ & $19.9(2.0)$ & $10.581(0.00)$ & -20.4 \\
\hline & \multirow[t]{3}{*}{ Wall thickness $(\mu \mathrm{m})$} & \multirow[t]{3}{*}{50} & A & $3.8(0.5)$ & $3.7(0.4)$ & $0.859(0.39)$ & -2.1 \\
\hline & & & B & $4.2(0.3)$ & $3.6(0.3)$ & $9.600(0.00)$ & -17.8 \\
\hline & & & $\mathrm{C}$ & $4.5(0.4)$ & $3.0(0.3)$ & $20.681(0.00)$ & -50.8 \\
\hline \multirow[t]{6}{*}{ Fiber tracheid } & \multirow[t]{3}{*}{ Diameter $(\mu \mathrm{m})$} & \multirow[t]{3}{*}{50} & A & $22.0(2.0)$ & $19.5(1.7)$ & $6.857(0.00)$ & -13.1 \\
\hline & & & $\mathrm{B}$ & $21.5(1.8)$ & $20.7(2.2)$ & $1.953(0.05)$ & -3.8 \\
\hline & & & $\mathrm{C}$ & $20.4(1.7)$ & $18.3(1.9)$ & $5.551(0.00)$ & -11.0 \\
\hline & \multirow[t]{3}{*}{ Wall thickness $(\mu \mathrm{m})$} & \multirow[t]{3}{*}{50} & A & $2.1(0.3)$ & $1.7(0.2)$ & $7.787(0.00)$ & -20.3 \\
\hline & & & B & $2.1(0.2)$ & $2.0(0.2)$ & $2.077(0.04)$ & -4.1 \\
\hline & & & $\mathrm{C}$ & $2.3(0.2)$ & $1.6(0.3)$ & $11.954(0.00)$ & -40.2 \\
\hline
\end{tabular}

The designation ' $n$ ' indicates the number of measured cells. Values in parentheses indicate standard deviations

$D R$ decrease ratio, which is the ratio of the upper side to the lower side upper and lower sides of sample A (Fig. 4). The same results were also obtained for samples B and C.

As shown in Fig. 5, the walls of both tracheids and fiber tracheids on the upper side of sample A were weakly stained by the phloroglucinol-HCl colour reaction when compared with those on the lower side. However, no marked changes in lignin distribution were observed by microscopy in the tracheid and fiber tracheid walls in the upper and lower sides of sample A after the Mäule colour reaction (Fig. 5). The same tendency was observed for both lignin colour reactions in samples B and C. Table 3 shows the VL absorbance of vessel, tracheid and fiber tracheid walls after the lignin colour reactions. The tracheid and fiber tracheid walls on the upper side showed significant decreases in VL absorbance after both lignin colour reactions in all samples, except for tracheids in sample B after the Mäule colour reaction (Table 3; Fig. 6). However, in vessel walls, changes in VL absorbance were mainly found after the phloroglucinol-HCl colour reaction (Table 3; Fig. 6). These results were similar to the trend observed for lignin content determined by the acetyl bromide method (Table 1). 
Fig. 4 Polarizing photomicrographs of unstained transverse sections in sample A of Gnetum gnemon. Asterisks and daggers indicate tracheids and fiber tracheids, respectively. Arrowhead indicates the $\mathrm{S}_{3}$ layer. Scale bar $=20 \mu \mathrm{m}$
Fig. 5 Photomicrographs of transverse sections on the upper side of Gnetum gnemon sample A after Mäule and phloroglucinol- $\mathrm{HCl}$ reactions. Asterisks and daggers indicate tracheids and fiber tracheids, respectively. Scale bar $=20 \mu \mathrm{m}$

\section{Upper side}

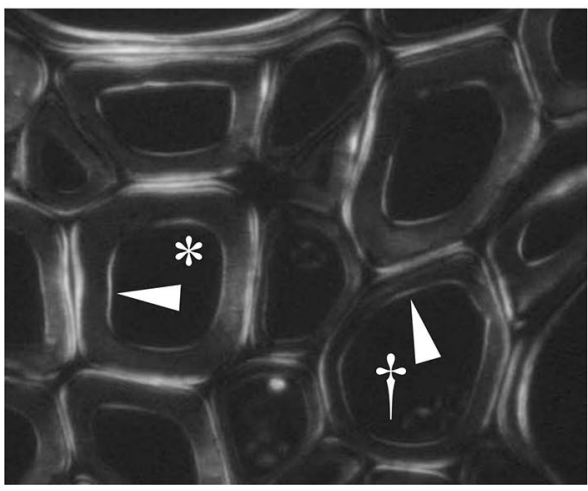

Lower side

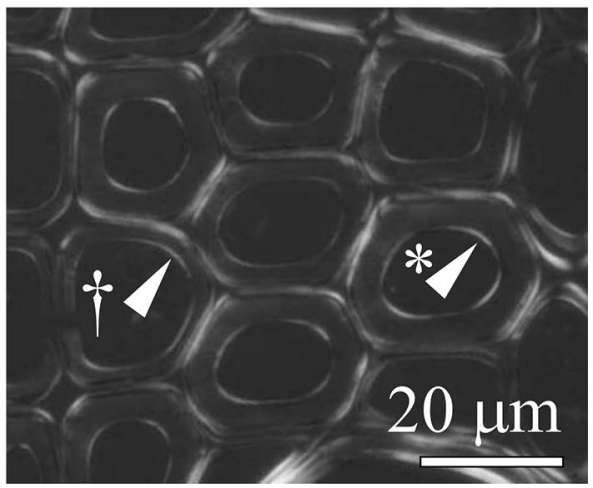

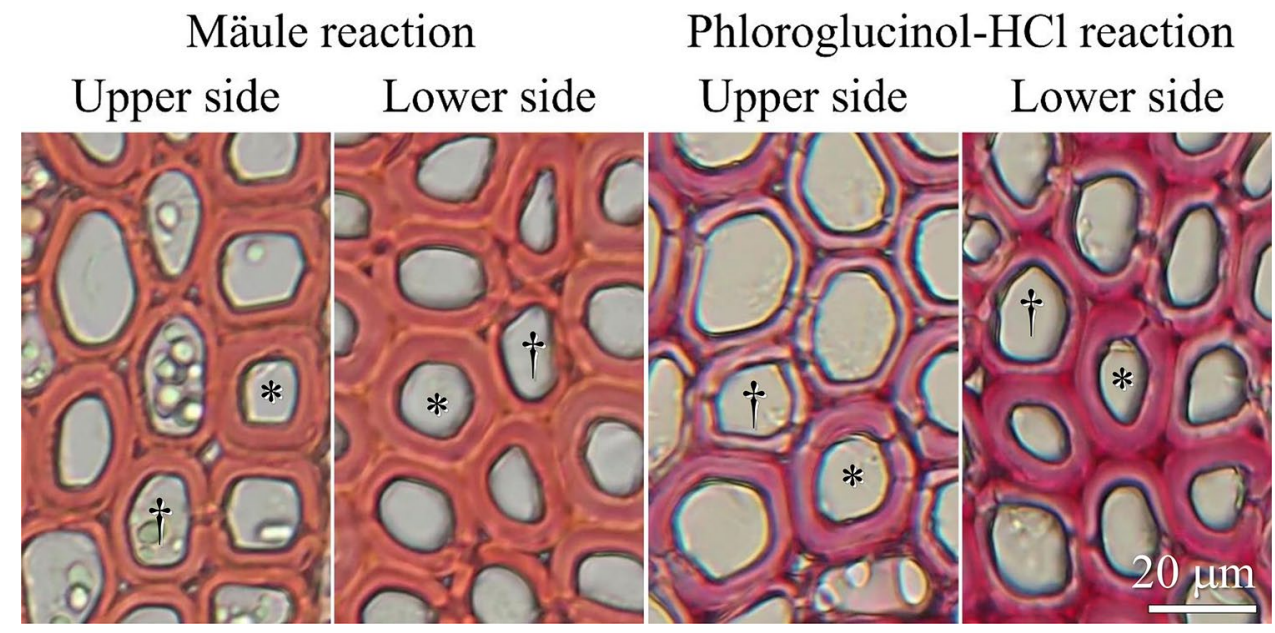

\section{Discussion}

\section{Reaction wood characteristics}

In general, those species that form reaction wood on the upper sides of inclined stems or branches show several common characteristics, including excessive tensile growth stress, eccentric growth, decreases in the diameter, frequency and lignin content of vessels and increases in cellulose content $[2,3,5-8,12]$. The reaction wood of these species is known as tension wood or 'tensionwood-like-reaction wood' $[2,3,6-8,12]$. The present study also did not detect any G-layer formation in these cells on the either the upper or lower sides of any sample (Fig. 5). Significant decreases in vessel frequency and MFA of tracheids were observed on the upper side of all samples (Table 1). Although significant decrease in lignin content on upper side was found only samples A and B (Table 1), both tracheid and fiber tracheid walls on the upper side of all samples were weakly stained by the phloroglucinol- $\mathrm{HCl}$ colour reaction when compared with those on the lower side (Table 3), suggesting decrease of lignin concentration in these cell walls. These results indicate that the anatomical and chemical changes due to reaction wood formation in G. gnemon tested here are similar to those in 'tension wood-like' type reaction wood in angiosperms $[2,8,12]$.

The reaction wood of G. gnemon stems showed excessive tensile growth stress and eccentric growth on the upper side [14]. In addition, significant difference was found on only MFA between normal wood and lateral and lower sides of inclined stems, however, other characteristics, such as G-layer formation, changes in anatomical and chemical characteristics, and air-dry density were not detected between wood from straight and inclined stems [14]. In the present study, the same tendency was obtained in eccentric growth and no G-layer formation on the upper side of inclined samples (Figs. 2, 5). These results suggest that reaction wood characteristics in G. gnemon are the same for both stems and branches. In addition, the results of this study showed significant decreases in vessel frequency, MFA, and VL absorbance in tracheids and fiber 
Table 3 Visible-light absorbance of cell walls in vessels, tracheids and fiber tracheids from the upper and lower sides of branches

\begin{tabular}{|c|c|c|c|c|c|c|c|}
\hline \multirow[t]{2}{*}{ Cell type } & \multirow[t]{2}{*}{ Absorbance $\left(\log I_{0} I^{-1}\right)$} & \multirow[t]{2}{*}{$n$} & \multirow[t]{2}{*}{ Sample } & \multicolumn{2}{|l|}{ Position } & \multirow[t]{2}{*}{$t$ value ( $p$ value) } & \multirow[t]{2}{*}{$D R(\%)$} \\
\hline & & & & Upper & Lower & & \\
\hline \multirow[t]{6}{*}{ Vessel } & \multirow[t]{3}{*}{ Mäule reaction (520 nm) } & \multirow[t]{3}{*}{5} & A & $0.29(0.03)$ & $0.32(0.04)$ & $1.184(0.27)$ & 9.4 \\
\hline & & & $\mathrm{B}$ & $0.27(0.08)$ & $0.27(0.03)$ & $0.029(0.98)$ & 0.0 \\
\hline & & & $\mathrm{C}$ & $0.20(0.04)$ & $0.30(0.04)$ & $3.799(0.01)$ & 33.1 \\
\hline & \multirow[t]{3}{*}{ Phloroglucinol- $\mathrm{HCl}$ reaction $(550 \mathrm{~nm})$} & \multirow[t]{3}{*}{5} & A & $0.48(0.03)$ & $0.56(0.03)$ & $4.956(0.00)$ & 15.8 \\
\hline & & & B & $0.49(0.03)$ & $0.54(0.02)$ & $2.691(0.03)$ & 9.2 \\
\hline & & & $\mathrm{C}$ & $0.46(0.01)$ & $0.49(0.01)$ & $4.376(0.00)$ & 6.9 \\
\hline \multirow[t]{6}{*}{ Tracheid } & \multirow[t]{3}{*}{ Mäule reaction (520 nm) } & \multirow[t]{3}{*}{5} & A & $0.33(0.02)$ & $0.36(0.03)$ & $2.060(0.07)$ & 8.3 \\
\hline & & & B & $0.32(0.06)$ & $0.34(0.01)$ & $0.104(0.43)$ & 6.8 \\
\hline & & & $\mathrm{C}$ & $0.31(0.03)$ & $0.40(0.05)$ & $3.240(0.01)$ & 20.8 \\
\hline & \multirow[t]{3}{*}{ Phloroglucinol- $\mathrm{HCl}$ reaction $(550 \mathrm{~nm})$} & \multirow[t]{3}{*}{5} & A & $0.23(0.01)$ & $0.31(0.04)$ & $4.563(0.00)$ & 25.7 \\
\hline & & & $\mathrm{B}$ & $0.24(0.02)$ & $0.39(0.01)$ & $15.421(0.00)$ & 37.6 \\
\hline & & & $\mathrm{C}$ & $0.28(0.00)$ & $0.43(0.02)$ & $13.740(0.00)$ & 35.7 \\
\hline \multirow[t]{6}{*}{ Fiber tracheid } & \multirow[t]{3}{*}{ Mäule reaction (520 nm) } & \multirow[t]{3}{*}{5} & A & $0.29(0.02)$ & $0.38(0.01)$ & $8.874(0.00)$ & 21.8 \\
\hline & & & $\mathrm{B}$ & $0.30(0.05)$ & $0.35(0.00)$ & $2.641(0.03)$ & 15.6 \\
\hline & & & $\mathrm{C}$ & $0.24(0.02)$ & $0.43(0.02)$ & $12.956(0.00)$ & 43.9 \\
\hline & \multirow[t]{3}{*}{ Phloroglucinol- $\mathrm{HCl}$ reaction $(550 \mathrm{~nm})$} & \multirow[t]{3}{*}{5} & A & $0.15(0.03)$ & $0.21(0.05)$ & $2.400(0.04)$ & 28.6 \\
\hline & & & B & $0.10(0.01)$ & $0.28(0.02)$ & $16.894(0.00)$ & 62.9 \\
\hline & & & $\mathrm{C}$ & $0.16(0.02)$ & $0.31(0.04)$ & $6.552(0.00)$ & 46.0 \\
\hline
\end{tabular}

The designation ' $n$ ' after lignin colour reactions indicates the number of replicates and measured cells. Values in parentheses indicate standard deviation

$D R$ decrease ratio, which is the ratio of the upper side to the lower side

Fig. 6 Visible-light absorption spectra of secondary walls of tracheids, fiber tracheids and vessels after Mäule and phloroglucinol- $\mathrm{HCl}$ colour reactions in Gnetum gnemon. 'A', 'B' and ' $\mathrm{C}$ ' in the figures correspond to sample codes. Solid and dotted lines indicate the upper and lower sides, respectively. Arrowheads in the figure indicate the absorbance at 520 and $550 \mathrm{~nm}$ for Mäule and phloroglucinol- $\mathrm{HCl}$ reactions, respectively

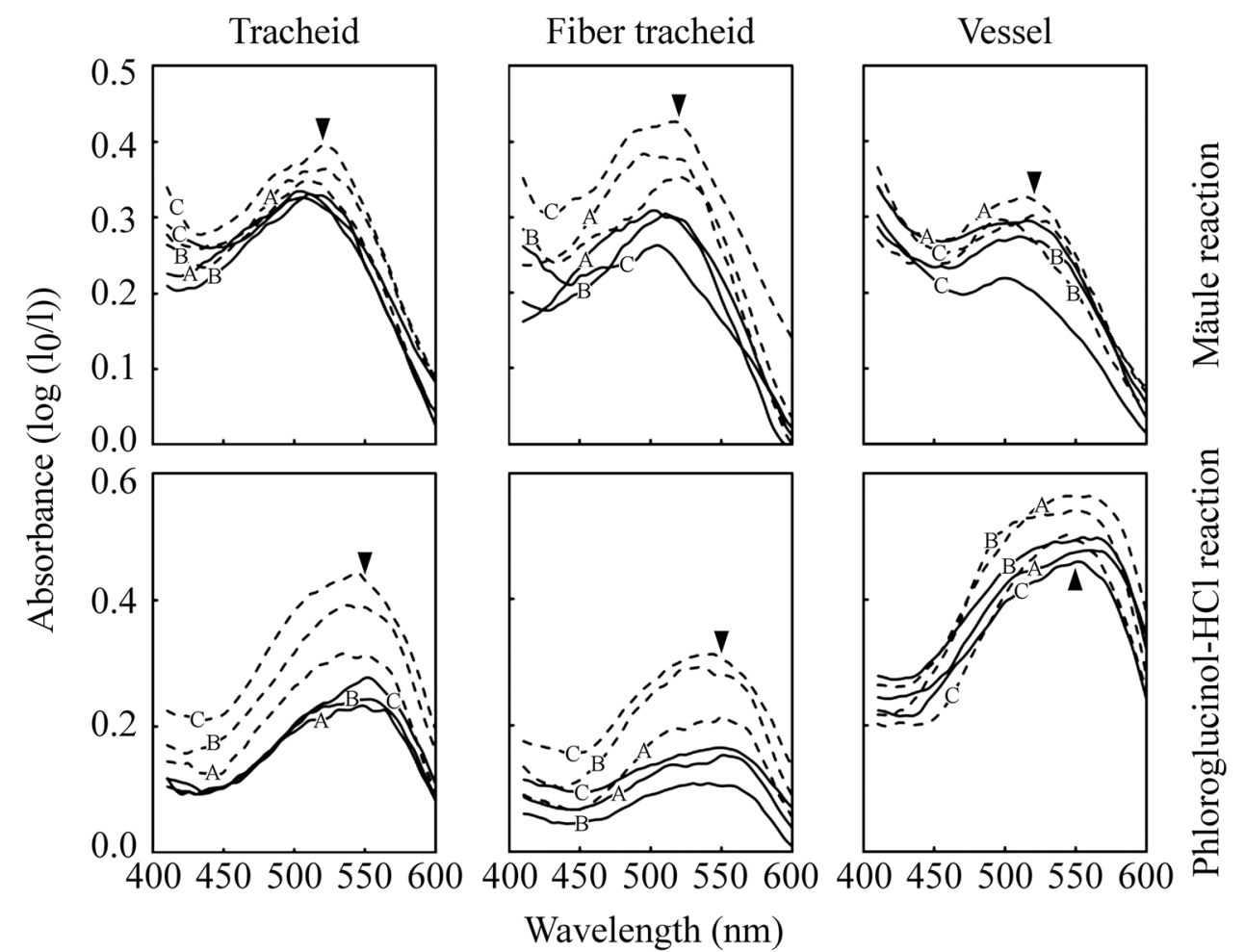


tracheid after phloroglucinol- $\mathrm{HCl}$ reaction on the upper sides of samples (Tables 1, 3; Figs. 5, 6).

\section{Relationship between the type of reaction wood and the proportion of syringyl to guaiacyl units in lignin}

We have previously pointed out that changes in the anatomical and chemical characteristics of secondary xylem due to reaction wood formation in vessel-less angiosperms might be related to the ratio of the syringyl to guaiacyl units in lignin in the cell walls of normal wood, which functions in mechanical support. Those species with a higher ratio of syringyl to guaiacyl units form reaction wood on the upper sides of inclined stems or branches, whereas the species with a low ratio of syringyl to guaiacyl units produce reaction wood on the lower sides of inclined stems or branches [11, 12]. However, this hypothesis was based only on results from tracheid walls of vessel-less angiosperms. The axial components of the secondary xylem in G. gnemon includes both tracheids and fiber tracheids [13] (Fig. 1), so both tracheid types can serve a mechanical support function in this species. Previous results obtained from the thioacidolysis method of wood meals indicated that the lignin in G. gnemon of normal wood is enriched in syringyl units compared with those in reaction wood [14]. In the present study, the fiber tracheid walls on the lower side were strongly stained with Mäule reagent, but not strongly with phloroglucinol- $\mathrm{HCl}$ reagent (Fig. 5). By contrast, both reagents stained the tracheid walls (Fig. 5). However, when compared to the vessel walls, the tracheid walls were only weakly stained with phloroglucinol- $\mathrm{HCl}$ reagent (Fig. 5). The tendencies on lignin concentration of fiber tracheid and tracheid walls on the lower side in this study were similar with the results on S/G ratio of normal wood reported by previous researchers [14]. Obtained results suggest that lignin of the fiber tracheid walls and tracheid walls on the lower side might be rich in syringyl units, although further researches, such as chemical analysis, are needed. Therefore, it can be concluded that our hypothesis regarding the relationships between reaction wood characteristics and the proportion of syringyl to guaiacyl units in lignin $[11,12]$ might also accept to gymnosperms with vessel element, $G$. gnemon as well as vessel-less angiosperms.

\section{Differences in the alteration patterns by reaction wood formation between tracheid and fiber tracheid}

As shown in Table 3 and Figs. 5 and 6, the patterns of alteration in lignin distribution due to reaction wood formation differed between tracheids and fiber tracheids. The VL absorbance measurements showed that the decrease ratios on the upper side to the lower side after the Mäule colour reaction ranged from 6.8 to $20.8 \%$ for tracheids and from 15.6 to $43.9 \%$ for fiber tracheids (Table 3). In addition, the decrease ratios on the upper sides after phloroglucinol- $\mathrm{HCl}$ reaction ranged from 25.7 to $37.6 \%$ for tracheids and from 28.6 to $62.9 \%$ for fiber tracheids (Table 3 ). These results suggest that the lignin content in the fiber tracheid cell walls is substantially decreased by reaction wood formation when compared to that in the tracheids. The reaction wood formation on upper side of inclined stems or branches could be related to increases in their longitudinal Young's modulus on the upper side [2]. Increases in the longitudinal Young's modulus in reaction wood occurs due to decreases in the MFA of the $\mathrm{S}_{2}$ layer and increases in the cellulose content in the secondary xylem cells that serve as mechanical support [2]. Generally, tracheids are the main axial component of the secondary xylem of gymnosperms and vessel-less angiosperms, and they function in both mechanical support and water conductance $[3,8]$. Conversely, fiber tracheids serve as mechanical support as well as libriform wood fibers in the secondary xylem of many angiosperms $[3,8]$. Therefore, the fiber tracheids of G. gnemon might serve mainly a mechanical support function, resulting in a greater decrease in the lignin content in the fiber tracheid walls than in the tracheid walls in response to an incline stimulus.

Acknowledgements This research was financially supported by JSPS KAKENHI Grant no. 15J07931.

\section{References}

1. Timell TE (1983) Origin and evolution of compression wood. Holzforschung 37:1-10

2. Okuyama T, Yamamoto H, Yoshida M, Hattori Y, Archer RR (1994) Growth stresses in tension wood: role of microfibrils and lignification. Ann For Sci 51:291-300

3. Evert RF (2006) Xylem: cell types and developmental aspects. In: Esau's plant anatomy. Wiley, New York, pp 291-322

4. Heinrich I, Gärtner H (2008) Variations in tension wood of two broad-leaced tree species in response to different mechanical treatments: implications for dendrochronology and mass movement studies. Int J Plant Sci 169:928-936

5. Yoshinaga A, Kusumoto H, Laurans F, Pilate G, Takabe K (2012) Lignification in poplar tension wood lignified cell wall layers. Tree Physiol 32:1129-1136

6. Roussel JR, Clair B (2015) Evidence of the late lignification of the G-layer in Simarouba tension wood, to assist understanding how non-G-layer species produce tensile stress. Tree Physiol 35:1366-1377

7. Aiso H, Ishiguri F, Toyoizumi T, Ohshima J, Iizuka K, Priadiand D, Yokota S (2016) Anatomical, chemical, and physical characteristics of tension woos in two tropical fast-growing species, Falcataria moluccana and Acacia auriculiformis. Tropics 25:33-41

8. Groover A (2016) Gravitropisms and reaction woods of forest trees-evolution, functions and mechanisms. New Phytol 211:790-802 
9. Yoshizawa N, Watanabe N, Yokota S, Idei T (1993) Distribution of guaiacyl and syringyl lignins in normal and compression wood of Buxus microphylla var. insularis Nakai. IAWA J 14:139-151

10. Aiso H, Hiraiwa T, Ishiguri F, Iizuka K, Yokota S, Yoshizawa N (2013) Anatomy and lignin distribution of "compression-woodlike reaction wood" in Gardenia jasminoides. IAWA J 34:263-272

11. Aiso H, Ishiguri F, Takashima Y, Iizuka K, Yokota S (2014) Reaction wood anatomy in a vessel-less angiosperm Sarcandra glabra. IAWA J 35:116-126

12. Aiso H, Ishiguri F, Ohkubo T, Yokota S (2016) Cell morphology and lignin distribution of reaction wood in Tetracentron sinense. IAWA J 37:372-382

13. Carlquist S (1994) Wood and bark anatomy of Gnetum gnemon L. Bot J Linnean Soc 116:203-221
14. Shirai H, Yamamoto H, Matsuo M, Yoshida M, Inatsugu M, Ko C, Fukushima K, Matsushita Y, Yagami S, Lahjie AM, Sawada M, Kule A (2015) Eccentric growth and growth stress in inclined stems of Gnetum gnemon. IAWA J 36:365-377

15. Tomlinson PB (2001) Reaction tissues in Gnetum gnemon a preliminary report. IAWA J 22:401-413

16. Tomlinson PB (2003) Development of gelatinous (reaction) fibers in stems of Gnetum gnemon (Gnetales). Am J Bot 90:965-972

17. Senft JF, Bendtsen BA (1985) Measuring microfibrillar angles using light microscopy. Wood Fiber Sci 17:564-567

18. Iiyama K, Wallis ALA (1988) An improved acetyl bromide procedure for determining lignin in woods and wood pulps. Wood Sci Technol 22:271-280 